J. Lake Sci.(湖泊科学), 2008, 20(1): 21-26

http://www.jlakes.org. E-mil: jlakes@niglas.ac.cn

(C2008 by Journal of Lake Sciences

\title{
太湖富营养化现状及原因分析
}

朱广伟

(中国科学院南京地理与湖泊研究所, 南京 210008)

摘 要: 根据 2005-2006 年太湖湖泊生态系统研究站的监测结果, 结合历史监测记录, 评价了近 5 年来太湖富营养化的趋势. 结果显示, 从 2000 年以来, 太湖的富营养化状况有加重趋势. 主要表现在: 1) 与历史监测资料对比, 近 5 年来无论梅梁湾还 是湖心区，夏季水体 TN、TP含量均呈增高趋势，如 1992-2001 年，太湖湖心区夏季 (6-8 月份)水体 TN 的平均值为 $1.706 \mathrm{mg} / \mathrm{L}$ (范围 1.238-2.266 mg/L), 而 2002-2006 这 5 年间该平均值为 $2.344 \mathrm{mg} / \mathrm{L}$ (范围 $1.924-2.717 \mathrm{mg} / \mathrm{L}$ ), 明显高于前 10 年 $(p=0.005$ ), 另外，同期湖心区夏季的水体透明度则明显下降(1992-2001 年夏季平均值为 $0.63 \mathrm{~m}$, 而 2002-2006 年则为 $0.34 \mathrm{~m}, p=0.003$ ); 2) 从野外调查看, 太湖夏季水华暴发的范围越来越大, 从 2000 年以前的梅梁湾、竺山湾及部分湖西区为主, 发展到 2006 年 的整个西太湖，夏季暴发水华的面积占太湖总面积的一半以上，且一年中出现水华的时间越来越长, 水华出现的频率越来越 高, 微囊藻水华为特征的藻型生态系统在大太湖似乎越来越稳定；3）近年来太湖沉水植物分布区的面积有所下降. 研究表明, 太湖近年来富营养化的现状不容乐观，原因可能与近几年异常的气候和水文条件有关，也可能与水草区的不断破坏而减弱了 微囊藻水华的生态竞争有关, 应引起有关部门重视.

关键词: 太湖; 富营养化; 营养状态指数; 微囊藻水华; 长期监测; 浅水湖泊

\section{Eutrophic status and causing factors for a large, shallow and subtropical Lake Taihu, China}

\section{ZHU Guangwei}

(Nanjing Institute of Geography and Limnology, Chinese Academy of Sciences, Nanjing 210008, P.R .China)

Abstract: As the third largest freshwater lakes of China and seriously suffered by Microcystis algal bloom in recent 20 years, Lake Taihu's eutrophic status had been analyzed based on the monthly monitoring data in recent 5 years. The analysis indicated that eutrophication of Lake Taihu became more and more serious since 2000. Comparing to the mean values in recent 5 years, the water quality variables like total nitrogen, total phosphorus, and transparency, water quality of Lake Taihu were worse than that between 1991 and 2001. The summer mean of TN between 2002 and 2006 was significantly higher than that of between 1992 and 2001 ( $p=$ 0.005). And the transparency mean of summer of 2002-2006 in center of Lake Taihu was only $0.34 \mathrm{~m}$, which was significantly lower than that of 1992-2001 with a mean $0.63 \mathrm{~m}(p=0.003)$. Moreover, Microcystis blooming areas in summer increased from about one fourth of the lake before 2000 to over half of the lake in 2006. Blooming season from June to October before 2000 also extend from May to December in 2006. Microcystis blooms occur more and more regularly in the lake. And dominant areas of submerged macrophytes decreased quickly. The deteriorate trend of eutrophication in Lake Taihu may partly due to the abnormal dry and hot climate in recent 2 years. However, destroy of submerged macrophytes also possibly contributed to the fast widespread of bloom.

Keywords: Lake Taihu; eutrophication; trophic state index; Microcystis algae bloom; long-term ecological monitoring; shallow lakes

太湖是我国第三大淡水湖, 面积 $2338 \mathrm{~km}^{2}$, 也是个浅水湖泊, 平均水深不到 $2 \mathrm{~m}^{[1]}$. 太湖又是我国最大 的存在严重蓝藻水华的湖泊，是国务院指定重点治理的富营养化水域之一 ${ }^{[2]} .20$ 世纪 60 年代，太湖略呈贫

* 中国科学院知识创新工程重要方向项目 (KZCX2-YW-419) 及国家自然科学基金重点项目 (40730529) 联合资助. 2007-01-18 收稿; 2007-07-27 收修改稿. 朱广伟, 男, 1972 年生, 博士，副研究员. 
营养状态, 1981年时仍属于中营养湖泊 ${ }^{[3]}$. 但从 20 世纪 80 年代后期, 太湖北部的梅梁湾开始频繁暴发蓝藻 水华 ${ }^{[3]}$. 太湖水体中有7个门的74种藻类被检出. 优势种是蓝藻中微囊藻(Microcystis)的几个种、水华鱼腥 藻(Anabaena flos-aquae)、硅藻中的颗粒直链藻(Aulacoseira granulate)、隐藻(Cryptomonas spp.) 及绿藻中 的栅藻(Scenedesmus)和盘星藻(Pediastrum) 等, 但危害最大的是微囊藻水华 ${ }^{[4]}$.

太湖治理从 20 世纪 90 年代后期得到了高度重视, 1998 年底对重点污染工业实施的“零点达标行动”, 流域污染物的输入得到一定控制 ${ }^{[5]}$. 从 1991-1999 年的监测情况来看, 1997 年以后水体的总氮、总磷及叶 绿素 $\mathrm{a}$ 含量等指标也均呈现下降趋势 ${ }^{[3]}$. 然而, 近期的研究发现, 在沉积物中积累了大量营养盐的情况下, 太湖的内源负荷相当大, 强烈的风浪扰动特点使得太湖沉积物与水体的营养盐交换频繁, 能够快速补充 水华暴发期间的营养盐需求 ${ }^{[6-8]} .2007$ 年 5 月 28 日至 6 月 3 日, 太湖的贡湖湾水厂又发生了严重的水危机 事件 ${ }^{[9]}$,太湖的蓝藻水华似乎越来越严重. 根据国际上类似治理湖泊的经验, 湖泊一旦发生富营养化, 往 往需要十年甚至几十年的长期控源才能恢复到较低的营养盐水平 ${ }^{[10-11]}$. 1998-1999 年的下降趋势是长期 趋势, 还是暂时现象? 需要进行后期的跟踪和分析.

本文在太湖站长期监测数据的基础上, 重点就 2005-2006 年太湖的富营养化趋势进行分析, 并对太 湖近几年富营养化过程的成因进行了探讨, 以期为太湖的治理提供科学依据.

\section{1 材料与方法}

\section{1 太湖生态因子的长期监测}

太湖湖泊生态系统研究站(TLLER)是中国生态监测网络之一, 是国家野外科学观测站. 从 1991 年起,

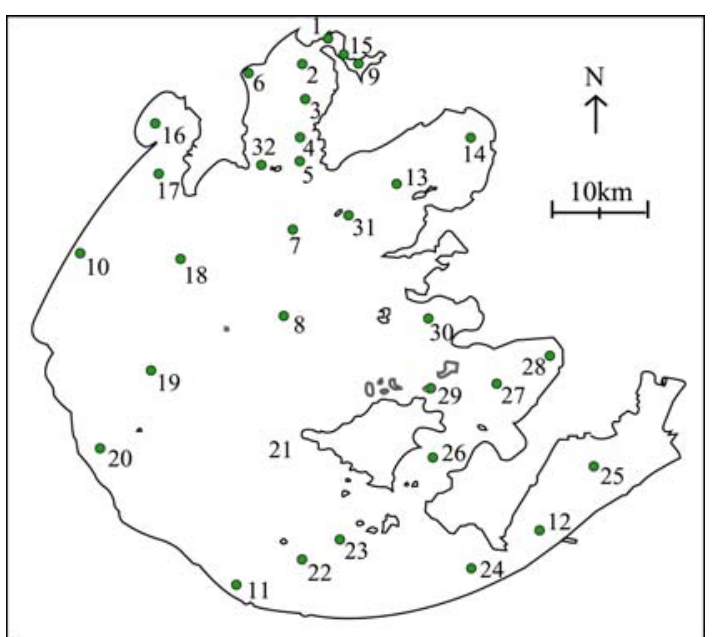

图 1 太湖湖泊生态系统研究站 在太湖设的监测点位

Fig.1 The sampling sites of Taihu Laboratory for

Lake Ecosystem Research in Lake Taihu TLLER 逐月或逐季度对太湖的营养盐、藻类、浮游动 物等生态因子进行观测. 监测点位图见图 1. 其中, 1991-1997年监测 1-8 号点 (逐月监测), 1998-2004 年 监测 1-13 号点 (其中 1-9 号点逐月监测, 10-13 号点 逐季度监测), 2005-2006 年监测 1-32 号点 (1-8、10、 13-14、16-17、32 点为逐月监测, 其余点位为逐季 度监测). 另外, 1991-2004 年还在 TLLER 附近设有 一个监测点. 监测的指标在逐年增多, 包括悬浮物 浓度 $(\mathrm{SS})$ 、透明度 $(\mathrm{SD})$ 、总氮 $(\mathrm{TN})$ 、总磷 $(\mathrm{TP})$ 、叶 绿素 a(Chl.a) 等富营养化基本参数, 以及水生生 物、常见离子、气象条件等. 样品的采集、分析等 均按照湖泊生态系统观测方法进行 ${ }^{[12]}$.

\section{2 数据的选取及处理}

在比较太湖富营养化的长期变化趋势时, 为提 高样点的代表性, 剔除靠近岸边的一些河口监测数 据, 分别选取 $2 、 3 、 4 、 5$ 号点代表梅梁湾的情况, 选 取 7、8 代表湖心区的情况，选取 6-8 月的监测结果 代表夏季的情况. 对梅梁湾和湖心区夏季水体 TN、 $\mathrm{TP} 、 \mathrm{SD}$ 及 $\mathrm{SS}$ 的长期变化进行统计分析.

在分析太湖近年来的富营养化空间分布状况时，选取 2005-2006 年 2、5、8、11 四个月的 32 个样点 监测数据, 取 Chl.a、SD 及 TP 数据, 按照蔡庆华等人提出的湖泊富营养化评价综合模型计算各点的营养 状态指数 $(T S I)^{[13]}$, 并将每年 4 个月的 $T S I$ 进行平均, 获得年 $T S I$ 值及其误差. 对 2005 年及 2006 年各点的 营养状态指数进行比较分析. TSI 的计算公式如下 ${ }^{[13]}$ :

$T S I=0.540$ TSI $(\mathrm{Chl})+0.297$ TSI $(\mathrm{SD})+0.163$ TSI $(\mathrm{TP})$

其中 $T S I(\mathrm{Chl}) 、 T S I(\mathrm{SD}) 、 T S I(\mathrm{TP})$ 则按照 Carlson 提出的营养状态指数计算方法获得 ${ }^{[14]}$, 计算公式:

$T S I(\mathrm{Chl})=10 \times(6-(2.04-0.68(\ln (\mathrm{Chl} . \mathrm{a}))) / \ln 2)$; 


$$
\begin{aligned}
& T S I(\mathrm{SD})=10 \times(6-\ln (\mathrm{SD}) / \ln 2) ; \\
& T S I(\mathrm{TP})=10 \times(6-\ln (48 / \mathrm{TP}) / \ln 2) .
\end{aligned}
$$

式中, Chl、SD、TP 分别代表水体 Chl.a 的浓度值 $(\mu \mathrm{g} / \mathrm{L}) 、 \mathrm{SD}(\mathrm{m})$ 及 $\mathrm{TP}$ 的浓度值 $(\mu \mathrm{g} / \mathrm{L})$.

\section{2 结果}

\section{1 夏季梅梁湾及湖心区水质的长期变化趋势}

太湖梅梁湾及湖心区夏季水体 TN、TP、SD 及 SS 的长期变化趋势(图 2). 与历史监测资料对比, 2001-2006 年近 5 年来无论梅梁湾还是湖心区，夏季水体 TN 含量都有明显增高的趋势，如 1992-2001 年, 太湖湖心区夏季水体 $\mathrm{TN}$ 的平均值为 $1.706 \mathrm{mg} / \mathrm{L}$ (范围 1.238-2.266 mg/L)，而 2002-2006 这 5 年间平均值为 $2.344 \mathrm{mg} / \mathrm{L}$ (范围 1.924-2.717 mg/L), 明显高于前 10 年的含量 $(p=0.005$ ). 另外, 比较同期夏季的水体 SD 也 反映出明显下降趋势 (如湖心区 1992-2001 年夏季平均值为 $0.63 \mathrm{~m}$, 而 2002-2006 年则为 $0.34 \mathrm{~m}, p=0.003$ ). 两个湖区的水质在 1995-1997 年高峰之后, 呈现了水质指标好转的趋势，N、P 浓度明显下降，悬浮物浓 度下降，透明度有所提高(图 2). 然而，从 2001 年开始，水质又开始呈明显恶化趋势. 水体 N、P 浓度逐年 上升，悬浮物浓度也快速上升，水体平均透明度持续下降. 至 2005 年，太湖水质的这几项指标已经劣于 1997 年. 2006 年梅梁湾夏季水体 TN 浓度平均为 $4.07 \mathrm{mg} / \mathrm{L}$ ，湖心区也达到 $2.64 \mathrm{mg} / \mathrm{L}$. 悬浮物浓度大多处 于 $50 \mathrm{mg} / \mathrm{L}$ 以上，而透明度则基本维持在 $0.30 \mathrm{~m}$ 以下. 从 2000 年以来太湖并没有进人明显的水质恢复期, 反而呈现出一定的恶化趋势.
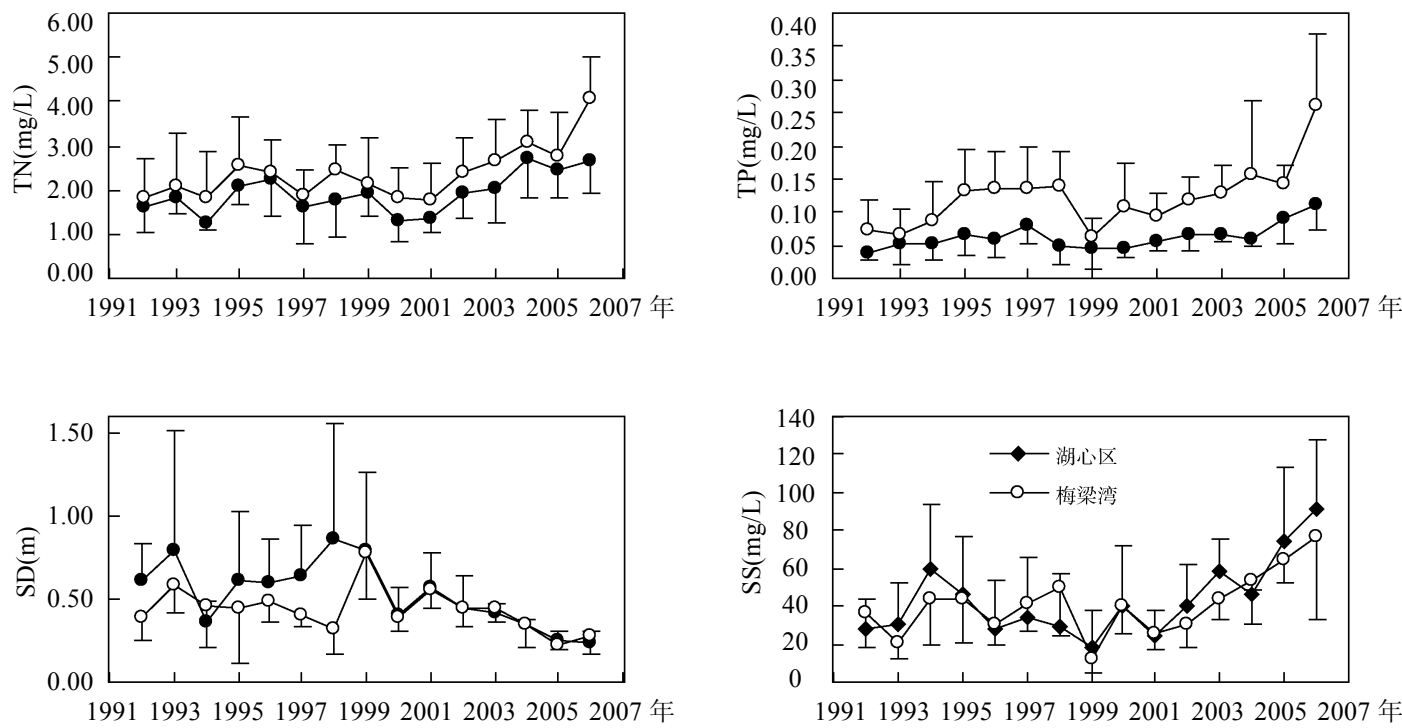

图 2 梅梁湾及湖心区夏季水体总氮 $(\mathrm{TN})$ 、总磷 $(\mathrm{TP})$ 、透明度 $(\mathrm{SD})$ 及悬浮物 $(\mathrm{SS})$ 浓度长期变化趋势 Fig.2 Variation of total nitrogen (TN), total phosphorus (TP), transparency (SD) and suspended solids (SS) in Meiliang Bay and center area of Lake Taihu in summer during 1991 to 2006

\section{2 太湖营养状态指数的时空变化特点}

除 19、22、23 三个点两年的 TSI 平均值基本相同外，其它点 2006 年的 TSI 平均值都超过了 2005 年 (图 3). 这反映出整个太湖 2006 年的水质普遍比 2005 年下降，包括水草区(12、14、24-28 号点).

事实上，从野外调查的观测看，2005 和 2006 年，太湖夏季暴发蓝藻水华的面积不断扩大. 贡湖湾的 北部(13、14 号点)，构成大片水草区的沉水植物群落在 2005 和 2006 年基本消失，只剩下零星的马来眼子 菜. 原来清澈见底的情况再也没有出现. 在以前较少出现水华的湖州小梅口一带(11 号点), 西山岛西侧 


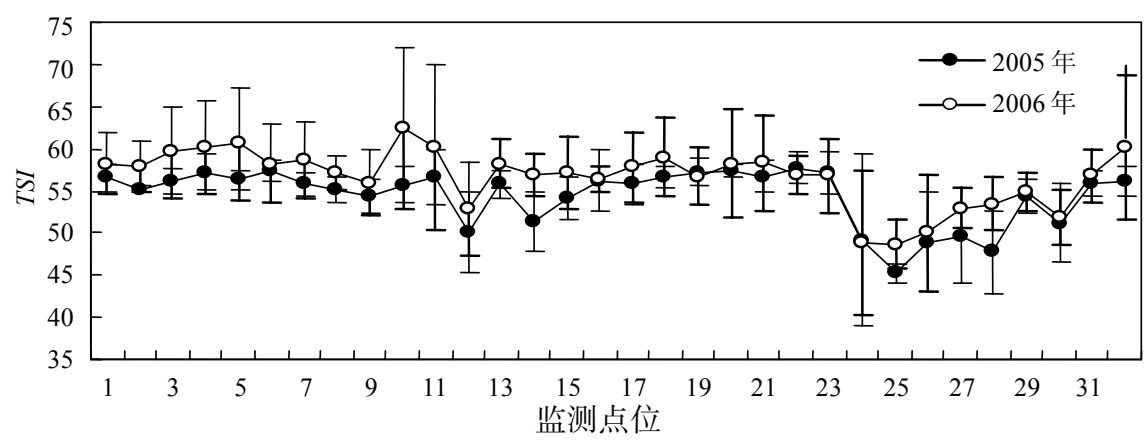

图 32005 年与 2006 年太湖 32 个监测点 TSI 值

Fig. 3 Trophic state index (TSI) of the 32 monitoring sites in Lake Taihu during 2005 to 2006

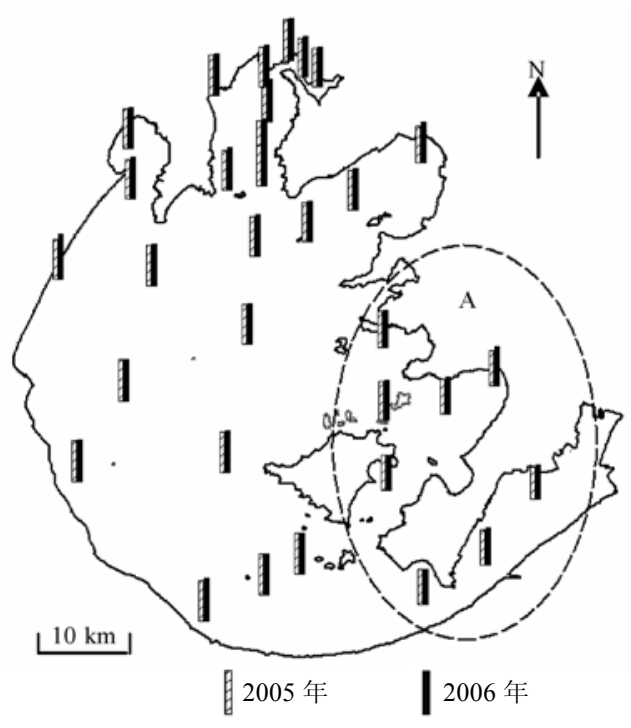

图 432 个监测点位 TSI 值的空间分布 (A 区为 2006 年 TSI 值小于 55 的点位分布) Fig.4 Spatial distribution of TSI in Lake Taihu
一带(19、20、21 号点), 甚至是东太湖的航道中(12、 25 号点 $)^{[15]}$, 这两年夏季都出现了大量的蓝藻水华, 并且 2006 年的夏季明显比 2005 年严重. 另外, 西 山岛南(23、24 号点)及西山岛与东山半岛之间(26、 $27 、 28$ 号点)的水草区沉水植物群落也明显退化. 2004 年这些地区主要以马来眼子菜、伊乐藻、苦草、 轮叶黑藻、狐尾藻等构成群落 ${ }^{[15]}$, 而 2005 年以后逐 步单一化, 以马来眼子菜及荇菜为主, 其他沉水植 物的比例大大下降, 在许多区域甚至消失.

由于是全年平均, 各点位间的差异不是非常大, 2006 年各点的 TSI 变幅为 49 至 63. 但是根据 2006 年的情况看, 水草区 TSI 值还是明显低于其他区域. 根据 2006 年 TSI 值的大小明显分成两个区, 东太 湖、胥口湾及渔洋山湾的 TSI 均低于 55 (点位 12 、 $24 、 25 、 26 、 27 、 28 、 29 、 30$ ) (图 4), 而其他点位 的 TSI 均高于 55. 这与实际监测时的情况非常吻合. 在这两年的监测过程中, 发现只有 A 区的沉水植物 群落还相对稳定. 另外贡湖湾的东南沿岸仍有较为 稳定的沉水维束管植物群落, 其他点位都观测到过 较为严重的蓝藻水华(五里湖的 9 号点和 15 号点也没有发现过水华), 包括贡湖湾最东侧的 14 号点.

\section{3 讨论}

与 20 世纪 90 年代相比太湖的藻型状态似乎变得越来越稳定. 对比 15 年来的监测结果(图 2), 近期太 湖的蓝藻水华仍未呈现好转趋势. 按照陈宇炜等的文献总结 ${ }^{[4]}$, 微囊藻水华的适应范围是水温 $20^{\circ} \mathrm{C}$ 以, 水体 TP 浓度 100-800 $\mu \mathrm{g} / \mathrm{L}, \mathrm{TN}$ 浓度 2.5-3.5mg/L, 以及适度浑浊的透明度条件将有利于微囊藻与其他藻 类竞争. 从 2000 年以前的监测情况看, 梅梁湾的 TP 含量平均值为 $113 \mu \mathrm{g} / \mathrm{L}$, 湖心区为 $76 \mu \mathrm{g} / \mathrm{L}^{[4]}$, 恰好接 近最佳磷浓度的下限. 而从 2006 年的情况看, 梅梁湾 2、3、4、5 点位的 TP 浓度年平均为 $176 \mu \mathrm{g} / \mathrm{L}$, 湖 心区 $7 、 8$ 点位为 $117 \mu \mathrm{g} / \mathrm{L}$, 这说明无论是梅梁湾还是湖心区, 夏季的总磷条件已经达到微囊藻水华的最 佳生长条件. 同样, 从 $\mathrm{TN}$ 和 SD 的情况看, 近期太湖, 尤其是湖心区及西南太湖, 都比以前更加适合水华 的发展. 因此, 近期蓝藻水华的恶化有可能是一个必然结果. 从生态系统的演替上看, 北太湖的藻型生 态系统也似乎趋于稳定, 以浮游藻类为主的生态系统变得越来越稳定. 而湖心区、西南湖区及贡湖湾的 部分湖区则正处于不断发展阶段, 今后以藻类为优势种的生态系统结构也很有可能变得越来越稳定. 
近期, 尤其是近两年, 太湖水华加剧也可能受反常的气候和水文影响. 2004-2006 年, 气候上出现了 明显的霉雨期缩短的现象. 5-8 月的天气与正常年份相比, 更加炎热和干旱. 与 2000 年相比, 尤其是夏季 的 8-9 月份, 近两年的水位明显偏高(图 5). 由 于太湖微囊藻较其竞争藻类具有更强的抗紫外 损伤能力 ${ }^{[16]}$, 而且水位偏高不利于沉水植物群 落的发展 ${ }^{[17-18]}$, 少雨、高温、充足的阳光和较 高的水位都更加有利于微囊藻水华的出现. 因 此, 近年反常的气候和水文条件也可能是造成 太湖蓝藻严重暴发的原因. 从流域其他水体的 情况看也反映出近几年气候对水质恶化的促进. 比如 2004 年, 由于流域夏季的降雨不足平均 年份的三分之一, 集水区径流量陡降, 钱塘江 首次在局部河段出现蓝藻水华 ${ }^{\circledR}$. 上游河道在 正常降雨年份还能够基本满足环境容量, 但在 比较干旱少雨的年份, 水质污染问题显得尤为 突出, 是引发水华出现的主要原因. 又如太湖 上游的天目湖水库, 2004 年的来水也异常少,

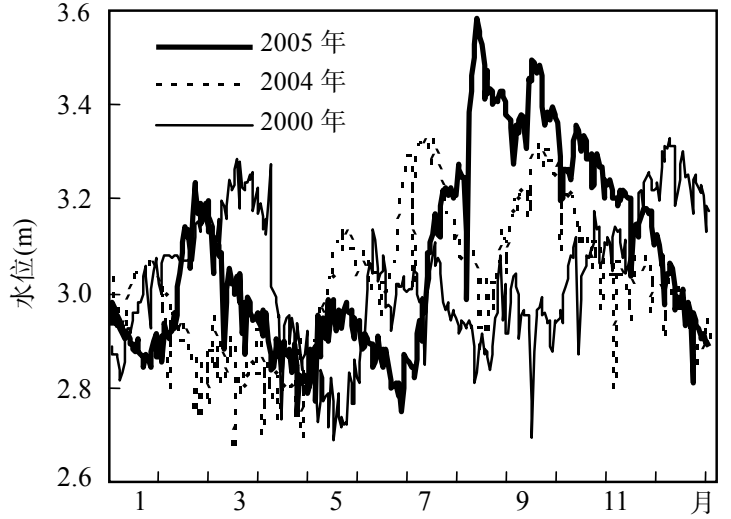

图 5 太湖站监测点水位变化

Fig.5 Fluctuation of water level in monitor site of Taihu Laboratory for Lake Ecosystem Research 水库基本没有进行泄洪 ${ }^{2}$. 异常气候条件导致 的流域水质全面恶化必然对太湖的蓝藻水华状况产生更为不利的影响. 这一成因分析在 2007 年的太湖 水危机事件中得到验证. 据分析, 2007 年贡湖湾水厂污水团的成因主要受以下几个因素影响: 1-4 月份的 水温高于正常年份，水位比正常年份低 $5 \mathrm{~cm}$ ，以及合适的风向 ${ }^{[9]}$. 事实上，除此之外，贡湖湾和梅梁湾流 场的改变也可能对水华的形成有贡献. 由于梅梁湾北部疏浚工程等影响, 2007 年上半年梅梁湾北部与河 道的交换量下降，而东部贡湖湾底部望虞河调水也因水流顶托作用而降低了梅梁湾的水量交换，相对安 静的水动力条件更加有利于水华的产生.

再次，太湖的水环境综合治理的力度仍不足. 近几年，尽管在国家的高度重视和支持下，太湖流域启 动了一系列旨在改善水质的科研、工程及研究示范项目, 如五里湖的综合治理工程、“引江济太”工程、 水源地水质保护工程示范等. 然而, 这些工程大多仍处于研究与示范阶段, 并未在全流域或全湖尺度上 展开, 其治理力度仍显得不够，治理效果也难以在近期显现出来. 因此，对太湖进一步的治理投人、更加 有效的管理还有待进一步的加强. 2007 年的太湖水危机事件之后, 江苏省进一步加强了流域治污力度, 提出“铁腕治污，科学治太”的流域管理方针，这一政策的严格贯彻将有助于太湖水质的好转.

\section{4 结论}

从近几年的监测结果看, 太湖的富营养化仍呈恶化趋势. 尤其是 2005-2006 年, 太湖的蓝藻水华暴 发持续时间加长，面积扩大，暴发频率也在加快，2007 年又暴发了饮用水危机事件. 另一方面，太湖东部 的水草区面积则在退缩, 水草的种群结构在恶化, 因此太湖的富营养化治理难度不容乐观.

从太湖的水质监测情况看, 2002-2006 年夏季太湖的营养盐浓度明显高于 20 世纪 90 年代, 透明度下 降, 2005-2006 年太湖湖心区所呈现出的水质特点比以前更加适宜微囊藻水华的发生. 藻型生态系统在梅 梁湾似乎已经进人稳定期，在湖心区、西南湖区及贡湖湾的部分湖区还在不断发展. 近几年夏季相对更 加干旱、少雨、高温的气候条件也可能加剧了太湖的蓝藻水华. 太湖的富营养化治理亟待更多和更加有 效的治理投人. 否则, 类似 2007 年的水危机事件出现的概率将会越来越大.

致谢: 太湖湖泊生态系统研究站提供了监测数据, 陈宇炜提供了 1991-1999 年的监测数据分析报告, 季江、

(1) 虞左明, 杭州市环境保护科学研究院, 私人通讯.

(2) 花志华, 溧阳天目湖开发区管理委员会, 私人通讯. 
钱荣树、张运林、龚志军、张路、高光、陈非洲、谷孝鸿、黄建明、汤祥明、蔡永久、王金、刘明亮等 参加了 2005-2006 野外生态调查工作, 在此表示感谢.

\section{5 参考文献}

[1] 秦伯强, 胡维平, 陈伟民等编著. 太湖水环境演化过程与机理. 北京: 科学出版社, 2004: 1-3.

[2] Qin Boqiang, Xu Pengzhu, Wu Qinglong et al. Environmental issues of Lake Taihu, China. Hydrobiologia, 2007, 581: 3-14.

[3] Chen Yuwei, Fan Chengxin, Teubner $\mathrm{K}$ et al. Changes of nutrients and phytoplankton chlorophyll-a in a large shallow lake, Taihu, China: an 8-year investigation. Hydrobiologia, 2003, 506/509: 273-279.

[4] Chen Yuwei,Qin Boqiang,Teubner K et al. Long-term dynamics of phytoplankton assemblages: Microcystis-domination in Lake Taihu, a large shallow lake in China. Journal of Plankton Research, 2003, 25(1): 445-453.

[5] 林泽新. 太湖流域水环境变化及缘由分析. 湖泊科学, 2002, 14(2): 111-116.

[6] 范成新, 张 路, 秦伯强等. 风浪作用下太湖悬浮态颗粒物中磷的动态释放估算. 中国科学(D 辑), 2003, 33(8): 760-768.

[7] Qin Boqiang, Zhu Guangwei, Zhang Lu et al. Estimation of internal nutrient release in large shallow Lake Taihu, China. Science in China, Series D: Earth Sciences, 2006, 49(Supp I): 38-50.

[8] Gao Guang, Zhu Guangwei, Qin Boqiang et al. Alkaline phosphatase activity and the phosphorus mineralization rate of Lake Taihu. Science in China, Series D: Earth Sciences, 2006, 49(Supp I): 176-185.

[9] 中国科学院南京地理与湖泊研究所. 太湖梅梁湾 2007 年蓝藻水华形成及取水口污水团成因分析与应急措施建议. 湖泊 科学, 2007, 19(4): 357-358.

[10] Scheffer M. Ecology of shallow lakes. The Netherlands, Dordretcht: Kluwer Academic Publishers, 2001: 289-307.

[11] Nixdorf B, Deneke R. Why 'very shallow' lakes are more successful opposing reduced nutrient loads. Hydrobiologia, 1997, 342/343: 269-284.

[12] 陈伟民主编. 湖泊生态系统观测方法. 北京: 中国环境科学出版社, 2004.

[13] 蔡庆华, 刘建康, King L. 评价湖泊富营养化的一个综合模型. 应用生态学报, 2002, 13(12): 1674-1678.

[14] Carlson RE. A trophic state index for lakes. Limnology and Oceanography, 1977, 22(2): 361-369.

[15] 水利部太湖流域管理局, 中国科学院南京地理与湖泊研究所. 太湖生态环境地图集. 北京: 科学出版社, 2000.

[16] Liu Z, Häder DP, Sommaruga R. Occurrence of mycosporine-like amino acids (MAAs) in the bloom-forming cyanobacterium Microcystis aeruginsa. Journal of Plankton Research, 2004, 26(8): 963-966.

[17] Van Geest GJ, Wolters H, Roozen FCJM et al. Water-level fluctuations affect macrophyte richness in floodplain lakes. Hydrobiologia, 2005, 539: 239-248.

[18] Havens KE, Sharfstein B, Brady MA et al. Recovery of submerged plants from high water stress in a large subtropical lake in Florida, USA. Aquatic Botany, 2004, 78: 67-82. 